\title{
Straggler to the A-Train
}

\author{
The successful launch of a carbon-observing satellite could make a start on tracking emissions shifts \\ around the globe.
}

Carbon dioxide sources and sinks can now be measured from space at high resolution since the Orbital Carbon Observatory 2 (OCO-2) successfully joined a constellation of six Earth-observing satellites, on 2 July.

Termed the Afternoon-Train (or A-Train) because it passes over the equator at $1.30 \mathrm{pm}$ each day, the satellite constellation already provides detailed data on clouds, aerosols, water, climate and air quality. The carbon dioxide measurements collected by the OCO-2 are expected to complement these observations with unprecedented details. The satellite will deliver regional-scale information on both carbon emissions, such as those from large metropolitan areas like Los Angeles, and carbon uptake by the terrestrial biosphere.

Most of the A-Train spacecraft were launched between 2002 and 2006. The designated lead craft, the original Orbiting Carbon Observatory, was set to join the constellation in February 2009. However, it was lost during launch and only now has it been possible to send its second incarnation, OCO-2, into orbit.

Global observations of carbon sources and sinks are now as important as ever. Over the past few years, the ranking of

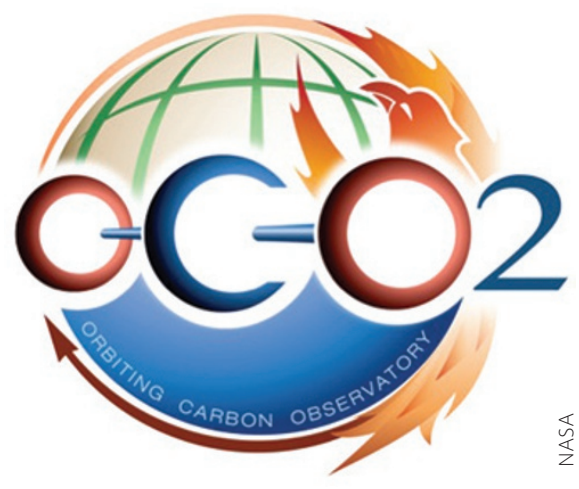

nations in terms of their total carbon emissions from fossil fuel burning and cement production has shifted from the developed world towards emerging economies, such as China, India and Brazil (Earth Syst. Sci. Data 6, 235-263; 2014). These countries typically do not have networks of sophisticated ground observations. Plans to improve the density of observational networks of local carbon budgets are largely limited to highly developed countries in Europe and North America (Nature Geosci. 2, 3-4; 2009). Worldwide coverage with satellite observations, at a resolution sufficient to identify emission or uptake hot spots, will help to close these observational gaps, which is key to understanding the human perturbations of the Earth's carbon cycle.

An important limitation of OCO-2 is its relatively short lifetime, currently set at only two years. To document how carbon emissions shift around the globe as the worldwide economy evolves, long-term monitoring would be better. Followup missions are already being planned, including a duplicate instrument that could be installed on the International Space Station - if the funds become available to follow through with the mission, after NASA's most recent budget omitted the project (Nature 510, 451-452; 2014).

The task of keeping the global carbon budget and its impact on the Earth's climate in check cannot be evaded. To that end, we need to know where emissions come from, where carbon is being taken up by ocean or land biosphere, and how sources and sinks evolve over time around the globe. Given the stakes, the funds to make these measurements on a long-term basis should be made available.

\section{Renewable versus sustainable}

\author{
Solar energy is undoubtedly renewable. We must make sure it is also as sustainable as possible.
}

So far, 2014 has been a good year for solar power. In February, the world's largest solar thermal power project opened about $65 \mathrm{~km}$ outside Las Vegas in the Mojave Desert (http://go.nature.com/P4cvjv). Long, sunny days in June meant record solar power generation in numerous European countries (http://go.nature.com/WjcbQm), and in July the price of electricity dropped to zero in the middle of the day in Queensland, Australia, driven largely by the use of rooftop solar panels (http://go.nature.com/Och7Hg).

Soaring solar power use is due partly to a huge drop in costs and a rise in production of the photovoltaic solar panels that convert sunlight to electricity. For the past 30 years, the cost of these solar panels has fallen by
$10 \%$ per year, while production has risen by $30 \%$ per year (Nature 507, 300-302; 2014). The surge in production comes mostly from China, now the world's biggest producer of solar panels. In China, the panels are produced for a much lower price compared with Europe and the US, but this monetary saving comes at a cost.

Less-energy-efficient production methods (Nature Geosci. 6, 507-509; 2013) mean that the carbon footprint of a solar panel made in China and used in Europe has been estimated to be almost twice that of a panel both made and used in Europe (Solar Energy 105, 669-678; 2014). In addition to the carbon footprint, environmental protection can be a concern (Nature 509, 563; 2014).
Further unintended consequences of solar panels may include shading the land, as well as modifying wind flow and the distribution of rainfall, and thereby soil moisture and nutrient cycles. The impact of giant parks of solar panels on local levels of carbon exchange between soil and the atmosphere is not yet understood. However, this must be considered in any carbon accounting of solar energy production.

If solar power is to play an important role in a sustainable future, the carbon footprints and environmental impact of the production, trade and use of solar panels must all be minimized. We need to look beyond maximum energy output at a minimum price tag. 